\title{
Permeabilitas dan Karakteristik Fisik Emulgel Minyak Atsiri Bunga Cengkeh dengan Penambahan Enhancer
}

\section{Permeability and Physical Characteristics Emulgel of Clove Oil with Addition of Enhancers}

\author{
Muhammad Fariez Kurniawan $^{*}{ }^{1}$, Nining Sugihartini ${ }^{2}$, Tedjo Yuwono ${ }^{2}$ \\ ${ }^{1}$ Program Studi Farmasi, Fakultas Kedokteran dan Ilmu Kesehatan Universitas \\ Muhammadiyah Yogyakarta \\ ${ }^{2}$ Fakultas Farmasi Universitas Ahmad Dahlan, Yogyakarta
}

Submitted : 25-07- 2018

Reviewed : 20 -08-2018

Accepted : 13-09-2018

\begin{abstract}
ABSTRAK
Eugenol, senyawa alami yang terdapat dalam minyak atsiri bunga cengkeh (MABC) sudah terbukti berkhasiat sebagai antiinflamasi. Diperlukan rancangan formulasi sediaan topikal untuk mendapatkan nilai flux, daya permeabilitas serta mempunyai karakteristik fisik yang memenuhi persyaratan. Untuk meningkatkan penetrasi eugenol menembus lapisan kulit ditambahkan komponen enhancer propilen glikol dan asam oleat dalam formulasi emulgel. Penelitian ini bertujuan untuk mengevaluasi nilai flux, daya permeabilitas, dan karakteristik fisik sediaan emulgel MABC dengan penambahan enhancer propilen glikol dan asam oleat. Enhancer kombinasi propilen glikol dan asam oleat ditambahkan ke dalam formula yang dibuat untuk meningkatkan nilai flux serta daya permeabilitas emulgel MABC. Dibuat 4 formula sediaan emulgel konsentrasi $10 \%$ MABC dengan ditambahkan enhancer $10 \%$ pada ketiga formula yang dibuat. Formula yang dibuat adalah F1 (ditambahkan propilen glikol 10 g), F2 (ditambahkan propilen glikol $5 \mathrm{~g}$ dan asam oleat $5 \mathrm{~g}$ ), F3 (ditambahkan asam oleat 10 g), F4 (tanpa penambahan enhancer). Parameter yang dicari dalam uji ini adalah nilai flux, daya permeabilitas, $\mathrm{pH}$, viskositas, daya lekat, daya sebar emulgel. Emulgel MABC dengan penambahan enhancer kombinasi propilen glikol dan asam oleat yang dihasilkan mempunyai nilai flux dan daya permeabilitas yang lebih besar daripada sediaan emulgel tanpa penambahan enhancer propilen glikol dan asam oleat serta mempunyai karakteristik fisik yang memenuhi persyaratan Enhancer propilen glikol dan asam oleat mampu secara signifikan meningkatkan nilai flux dan daya permeabilitas eugenol menembus lapisan stratum corneum kulit dan memiliki karakteristik fisik berupa nilai $\mathrm{pH}$, viskositas, daya lekat dan daya sebar yang memenuhi kriteria
\end{abstract}

Kata kunci : emulgel, enhancer, flux, permeabilitas, karakteristik fisik

\begin{abstract}
Eugenol, a natural compound contained in clove oil (MABC) has been proven efficacious as anti-inflammatory. Topical dossage forms design is required to obtain flux value, permeability and have physical characteristics that suitable with the requirements. To increase eugenol penetration through the skin layer added propylene glycol and oleic acid as
\end{abstract}


enhancer components in the emulgel formulation. This study aims to evaluate the flux value, permeability, and physical characteristics of MABC emulgel with the addition of propylene glycol and oleic acid as enhancers. A combination enhancers of propylene glycol and oleic acid was added to the formula prepared to increase the flux value and the permeability of the $\mathrm{MABC}$ emulgel. Four formula of emulgel MABC were prepared with a $10 \%$ enhancer added in all three formulas prepared. The formula prepared was F1 (added propylene glycol $10 \mathrm{~g}$ ), F2 (added propylene glycol $5 \mathrm{~g}$ and $5 \mathrm{~g}$ oleic acid), F3 (10 g oleic acid added), F4 (without addition enhancer). The parameters in this test was flux value, permeability, $\mathrm{pH}$, viscosity, adhesive test, and spreading test. The MABC Emulgel with the addition of enhancer combination of propylene glycol and oleic acid has a flux value and a greater permeability than emulgel without the addition of propylene glycol and oleic acid as enhancers and has a physical characteristic that suitable with the requirements. Enhancers of propylene glycol and oleic acid were able to significantly increase the value of flux and eugenol permeability permeability through the stratum corneum layer of skin and have physical characteristics such as $\mathrm{pH}$ value, viscosity, adhesion and spreading capacity that suitable with the criteria.

Keyword : emulgel, enhancer, flux, permeability, physical characteristics

\section{Penulis korespondensi:}

Muhammad Fariez Kurniawan

Program Studi Farmasi, Fakultas Kedokteran dan Ilmu Kesehatan Universitas Muhammadiyah Yogyakarta

Email: muhammadfariez@yahoo.co.id / fariez@umy.ac.id

\section{PENDAHULUAN}

Eugenol yang merupakan minyak atsiri utama yang terdapat dalam kuncup bunga cengkeh yang telah terbukti berefek sebagai antiinflamasi. Eugenol, telah diketahui mempunyai potensi sebagai anti inflamasi terhadap enzim siklooksigenase-2 dan enzim lipooksigenase-15. Eugenol menujukkan efek sebagai inhibitor yang kuat terhadap siklooksigenase-2 $(58,15 \%)$ dan lipooksigenase-15 $(86,15 \%)$ pada konsentrasi $10 \mu \mathrm{g} / \mathrm{ml}$ dan $25 \mu \mathrm{g} / \mathrm{ml}$ (Kamatou, Vermaak and Viljoen, 2012).

Potensi MABC ini layak dikembangkan dalam bentuk sediaan topikal antiinflamasi yang tepat. Emulgel dipilih karena dapat menghantarkan zat aktif yang bersifat hidrofobik, namun tidak kehilangan sifat-sifat dari gel yaitu mempunyai efek rasa dingin ketika digunakan dan mudah dicuci dengan air (Khullar et al., 2012). Pada penelitian yang dilakukan Sari dkk (2015) menunjukkan bahwa emulgel MABC dengan konsentrasi 10\% yang dibuat memiliki karakteristik fisik yang baik dan tidak mengiritasi kulit hewan uji. Pengembangan formulasi sediaan topikal perlu dilakukan karena penghantaran obat melewati kulit sering mengalami permasalahan dalam proses penetrasi obat menembus lapisan kulit terutama stratum corneum. Lapisan ini merupakan pembatas yang menentukan laju, yang menahan keluar masuknya zat-zat kimia sehingga menghalangi penetrasi obat melalui kulit (Chantasart and Kevin Li, 2012). Sehingga dalam pengembangan yang akan dilakukan, formulasi emulgel ditambahkan enhancer kombinasi propilen glikol dan asam oleat dengan tujuan untuk meningkatkan daya penetrasi MABC menembus stratum corneum kulit sehingga efek anti inflamasi yang didapatkan akan lebih cepat dan optimal.

Propilen glikol mampu meningkatkan permeabilitas obat yang digunakan secara topikal (Trommer and Neubert, 2006), meningkatkan permeabilitas natrium diklofenak dalam basis carbopol (Arellano et al., 1999). Propilen glikol jika dikombinasikan dengan asam oleat akan menghasilkan efek sinergis dalam meningkatkan penetrasi obat (Raut et al., 2014). Berdasarkan penelitian, komposisi optimum campuran asam oleat, propilen glikol, dan minyak atsiri temulawak dalam fraksi etil asetat ekstrak teh hijau berdasarkan Simplex 
Lattice Design dapat meningkatkan permeabilitas epigalokatekin galat dalam ekstrak teh hijau (Sugihartini, 2013). Emulgel MABC dengan enhancer kombinasi propilen glikol dan asam oleat yang dibuat harus memiliki karakteristik fisik yang baik, meliputi nilai $\mathrm{pH}$, viskositas, daya lekat, dan daya sebar yang sesuai dengan kulit dan juga tidak menimbulkan iritasi pada kulit. Pada penelitian sebelumnya emulgel MABC memiliki karakteristik fisik yang baik dan tidak mengiritasi kulit hewan uji (Sari, Sugihartini and Yuwono, 2015).

\section{METODE PENELITIAN}

\section{Alat dan Bahan}

Alat-alat yang digunakan dalam penelitian ini adalah instrumen KCKT (HPLC Shimadzu 00854L207049), alat uji difusi tegak Franz, alat-alat gelas Iwaki Pyrex ${ }^{\circledR}$, waterbath Memmerth ${ }^{\circledR}$, alat uji daya lekat salep, alat uji daya sebar salep, pH meter SevenEasy Mettler Toledo ${ }^{\circledR}$, timbangan digital Mettler Toledo ${ }^{\circledR}$, viscometer Brookfiled DV1 Prime $^{\circledR}$, dan ultra thurax IKA T18 Digital Homogenizer ${ }^{\circledR}$.

Bahan yang digunakan dalam penelitian ini adalah minyak atsiri bunga cengkeh (MABC) yang diperoleh dari Center of Essential Oil Studies (CEOS) Universitas Islam Indonesia, Yogyakarta. Bahan tambahan lain yang digunakan dalam formulasi sediaan emulgel adalah pharmaceutic grade meliputi carbopol 940, trietanolamin, propilen glikol, asam oleat, paraffin cair, sorbitol, span 80 , tween 80 , metil paraben, propil paraben, aquadest. Semua bahan untuk formulasi emulgel diperoleh dari PT Brataco Chemica Yogyakarta. Kulit hewan uji yang digunakan berasal dari kulit punggung tikus putih jatan galur Sprague-dawley usia 2-3 bulan. Alat uji daya lekat salep ditunjukkan dalam gambar 1, sedangkan alat sel difusi tegak Franz diperlihatkan dalam gambar 2.

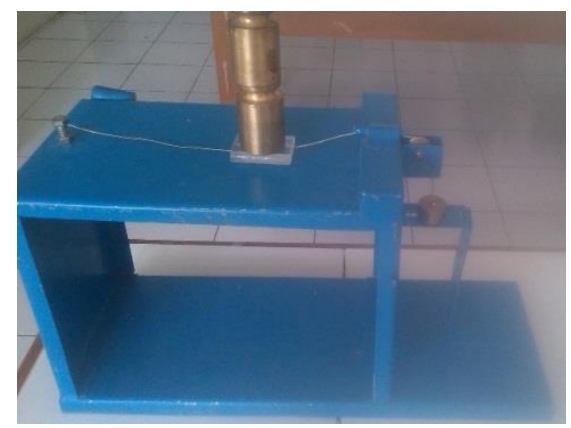

Gambar 1. Alat uji daya lekat

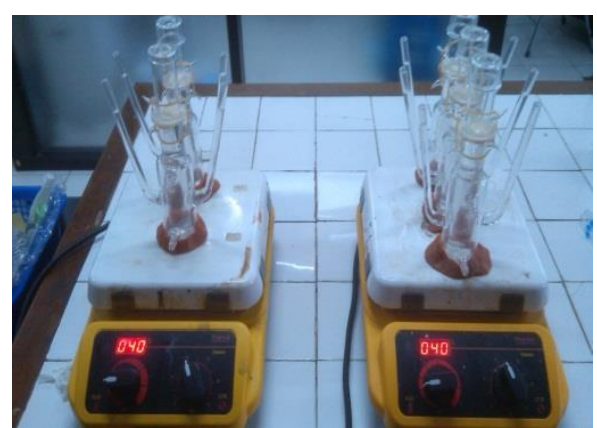

Gambar 2. Alat uji difusi tegak Franz

\section{Jalannya Penelitian}

\section{Formulasi emulgel}

Formulasi emulgel MABC disajikan dalam Tabel I. Formula dirancang dengan penambahan kombinasi enhancer propilen glikol dan asam oleat dengan bobot total $10 \mathrm{~g}$ di mana Formula 1 (F1) ditambahkan $10 \mathrm{~g}$ propilen glikol, Formula 2 (F2) ditambahkan 5 g propilen glikol dan $5 \mathrm{~g}$ asam oleat, sedangkan Formula 3 (F3) ditambahkan 10 asam oleat, serta F4 yang merupakan emulgel yang tidak ditambahkan enhancer yang digunakan sebagai kelompok kontrol. Jumlah MABC yang digunakan dalam formulasi adalah $10 \mathrm{~g}$. 
Tabel I. Formulasi emulgel minyak atsiri bunga cengkeh

\begin{tabular}{lcccc}
\hline \multirow{2}{*}{ Bahan } & \multicolumn{4}{c}{ Formula (gram) } \\
\cline { 2 - 5 } & F1 & F2 & F3 & F4 \\
\hline MABC & 10 & 10 & 10 & 10 \\
Carbopol 940 & 4 & 4 & 4 & 4 \\
TEA & 8 & 8 & 8 & 8 \\
Sorbitol & 2 & 2 & 2 & 2 \\
Parafin cair & 1,25 & 1,25 & 1,25 & 1,25 \\
Span 80 & 2,5 & 2,5 & 2,5 & 2,5 \\
Tween 80 & 17,5 & 17,5 & 17,5 & 17,5 \\
Metil paraben & 0,18 & 0,18 & 0,18 & 0,18 \\
Propil paraben & 0,02 & 0,02 & 0,02 & 0,02 \\
Propilen glikol & 10 & 5 & - & - \\
Asam oleat & - & 5 & 10 & - \\
Aquadest ad & 100 & 100 & 100 & 100 \\
\hline
\end{tabular}

Keterangan :

F1 : emulgel MABC dengan penambahan enhancer propilen glikol $10 \mathrm{~g}$

F2 : emulgel MABC dengan penambahan enhancer propilen glikol $5 \mathrm{~g}$ dan asam oleat $5 \mathrm{~g}$

F3 : emulgel MABC dengan penambahan enhancer asam oleat $10 \mathrm{~g}$

F4 : emulgel MABC tanpa penambahan enhancer

\section{Evaluasi Daya Permeabilitas}

Uji ini dilakukan dengan menggunakan alat uji difusi tegak Franz. Membran yang digunakan menggunakan kulit punggung tikus yang telah dibersihkan dari lapisan lemak dan pembuluh darah yang menempel kemudian diletakkan di antara kompartemen donor dan aseptor. Kompartemen donor berisi satu gram emulgel sedangkan aseptor berupa larutan dapar fosfat $\mathrm{pH} 7,4$ sebanyak $50 \mathrm{~mL}$. Selama uji transport kompartemen aseptor dijaga pada suhu $37^{\circ} \mathrm{C}$ dan diberi pengadukkan dengan stirrer pada skala 6. Sejumlah 1,0 $\mathrm{ml}$ larutan sampel diambil dari kompartemen aseptor dalam rentang waktu 26 jam $(0,5 ; 1$; $2 ; 3 ; 4 ; 5 ; 6 ; 24$ dan 26 jam). Setiap kali setelah pengambilan sampel maka langsung ditambahkan 1,0 ml larutan dapar fosfat $\mathrm{pH}$ 7,4. Selanjutnya eugenol dalam setiap sampel ditetapkan nilai AUC nya dengan instrumen HPLC untuk kemudian dihitung kadarnya. Fase gerak yang digunakan adalah acetonitrile : asam asetat 1\% (80:20). Fase diam yang digunakan adalah kolom C18 dan kecepatan waktu alirnya $1 \mathrm{ml} / \mathrm{menit}$ dengan panjang gelombang $280 \mathrm{~nm}$. Berdasarkan nilai AUC yang diperoleh dihitung nilai flux dan daya permeabilitasnya.

\section{Evaluasi Karakteristik Fisik Emulgel}

Uji pH dilakukan dengan cara 0,5 gram emulgel diencerkan dalam $5 \mathrm{ml}$ aquadest, kemudian dicek $\mathrm{pH}$ nya menggunakan $\mathrm{pH}$ meter (Naibaho, Yamlean and Wiyono, 2013).Uji daya sebar dilakukan dengan cara 0,5 gram emulgel diletakkan di atas kaca bulat, kaca lainnya diletakkan di atasnya dan dibiarkan selama 5 menit. Diameter sebar emulgel diukur, kemudian ditambahkan beban $50 \mathrm{~g}$ dan didiamkan selama 1 menit kemudian diukur diameternya. Kemudian ditambahkan lagi beban $100 \mathrm{~g}$ dan diukur diameternya (Naibaho, Yamlean and Wiyono, 2013). Uji daya lekat dilakukan dengan cara 0,25 gram emulgel diletakkan di atas objek gelas yang telah ditentukan luasnya. Objek gelas yang lain diletakkan di atasnya. Kemudian objek gelas dipasang pada alat uji dan diberi beban $1 \mathrm{~kg}$ selama 5 menit. Beban $1 \mathrm{~kg}$ dilepas beserta beban penyangga $80 \mathrm{~g}$ 
dan dicatat waktunya hingga kedua objek gelas tersebut terlepas (Naibaho, Yamlean and Wiyono, 2013). Pengukuran viskositas dan penentuan sifat alir dilakukan dengan menggunakan alat viscometer Brookfiled DV-1 Prime ${ }^{\circledR}$.

\section{HASIL DAN PEMBAHASAN}

Parameter flux menggambarkan kecepatan dan jumlah zat melalui suatu bidang dengan luas $1 \mathrm{~cm}^{2}$ per satuan waktu. Nilai flux dikalkulasikan dari nilai slope hasil regresi linier hubungan antara waktu (t) vs jumlah obat per satan luas permukaan membran (MFk/A) (Rakesh dan Anoop, 2012). Semakin besar nilai flux maka kecepatan penetrasi obat dalam menembus lapisan kulit akan semakin besar (Banweer, Pandey and Pathak, 2010). Hasil uji permeabilitas menunjukkan formula 3 dengan komposisi enhancer $100 \%$ asam oleat memiliki nilai flux paling besar dibandingkan formula yang lainnya. Menurut (Engelbrecht $e t$ al., 2011) asam oleat mempunyai kemampuan penetrasi yang besar menembus lapisan stratum korneum karena mempunyai dua mekanisme yaitu melalui interkalasi pada lapisan lipid lamella dan meningkatkan degradasi rantai alkil pada struktur startum korneum.

Berdasarkan hasil penelitian, perbandingan nilai flux $\mathrm{F} 3\left(0,1090 \mathrm{mg} / \mathrm{cm}^{2} / \mathrm{jam}\right)>\mathrm{F} 1$ $\left(0,0752 \mathrm{mg} / \mathrm{cm}^{2} / \mathrm{jam}\right)>\mathrm{F} 2\left(0,0610 \mathrm{mg} / \mathrm{cm}^{2} / \mathrm{jam}\right)>\mathrm{F} 4\left(0,0568 \mathrm{mg} / \mathrm{cm}^{2} / \mathrm{jam}\right)$. Pada formula 1 dan 2 memiliki nilai flux yang lebih rendah jika dibandingkan dengan formula 3, namun masih lebih tinggi daripada formula 4. Hal ini membuktikan bahwa propilen glikol dan asam oleat sebagai enhancer mampu meningkatkan kemampuan penetrasi eugenol dalam menembus lapisan stratum corneum. Propilen glikol dapat meningkatkan harga flux dengan cara berinteraksi dengan bilayer fosfolipid yang dapat membuat lapisan kulit menjadi fleksibel sehingga penetrasi obat dalam menembus lapisan kulit akan semakin meningkat (Elmoslemany et al., 2012). Dari hasil yang didapatkan dapat diketahui bahwa asam oleat mempunyai efek yang lebih besar dalam meningkatkan flux emulgel MABC dibandingkan propilen glikol dan kombinasi propilen glikol dengan asam oleat.

Parameter permeabilitas digunakan untuk menunjukan kemampuan dari suatu membran untuk dapat dilewati suatu obat. Semakin besar nilai permeabilitas akan meningkatkan penetrasi obat dalam menembus lapisan kulit (Banweer, Pandey and Pathak, 2010). Nilai permeabilitas diperoleh dari hasil pembagian antara nilai flux dengan konsentrasi emulgel MABC dalam uji. (Rakesh dan Anoop, 2012). Nilai permeabilitas sebanding dengan nilai flux. Semakin besar nilai flux maka nilai permeabilitas juga akan semakin besar, karena berdasarkan persamaan nilai koefisien permeabilitas adalah harga flux/Cp (Rakesh dan Anoop, 2012). Berdasarkan hasil penelitian, perbandingan nilai permeabilitas F3 $\left(3,02 \times 10^{-7} \mathrm{cmdetik}^{-1}\right)>\mathrm{F} 1\left(2,08 \times 10^{-7} \mathrm{cmdetik}^{-1}\right)>\mathrm{F} 2\left(1,69 \times 10^{-7} \mathrm{cmdetik}^{-1}\right)>$ F4 $\left(1,57 \times 10^{-7} \mathrm{cmdetik}^{-1}\right)$. Hasil penelitian menunjukkan bahwa propilen glikol dan asam oleat sebagai enhancer mampu meningkatkan kemampuan permeabilitas pada sediaan emulgel secara signifikan dibandingkan dengan kelompok Formula 4. Data hasil uji permeabilitas diperlihatkan dalam tabel II.

Tabel II. Data hasil uji permeabilitas eugenol antar formula

\begin{tabular}{ccccc}
\hline $\begin{array}{c}\text { Parameter Uji } \\
\text { Permeabilitas }\end{array}$ & F1 & F2 & F3 & F4 \\
\hline Flux & $0,0752 \pm$ & $0,0610 \pm$ & $0,1090 \pm$ & $0,0568 \pm$ \\
$\left(\mathrm{mg} / \mathrm{cm}^{2} / \mathrm{jam}\right)$ & 0,0014 & 0,0018 & 0,0025 & 0,0024 \\
& & & & \\
Permeabilitas & $2,08 \times 10^{-7} \pm$ & $1,69 \times 10^{-7} \pm$ & $3,02 \times 10^{-7} \pm$ & $1,57 \times 10^{-7} \pm$ \\
$(\mathrm{cm} /$ detik $)$ & $4,08 \times 10^{-9}$ & $5,13 \times 10^{-9}$ & $7,17 \times 10^{-9}$ & $6,83 \times 10^{-9}$ \\
\hline
\end{tabular}


Keterangan :

$\mathrm{F} 1$ : emulgel MABC dengan penambahan enhancer propilen glikol $10 \mathrm{~g}$

F2 : emulgel MABC dengan penambahan enhancer propilen glikol $5 \mathrm{~g}$ dan asam oleat $5 \mathrm{~g}$

F3 : emulgel MABC dengan penambahan enhancer asam oleat $10 \mathrm{~g}$

F4 : emulgel MABC tanpa penambahan enhancer

Evaluasi karakteristik fisik emulgel meliputi uji viskositas, uji daya lekat, uji daya sebar dan uji pH. Emulgel yang dihasilkan dari F1, F2 dan F3 mempunyai tampilan fisik yang baik dengan warna putih kekuningan. Konsistensi F1 lebih padat daripada F2, dan F2 lebih padat daripada F3. Berdasarkan rheogram pada gambar 3 terlihat bahwa emulgel F1, F2, F3 yang dibuat memiliki sifat alir non newton yaitu sifat alir plastis karena kurva tidak memotong titik 0,0 menunjukkan adanya yield value yang harus dilampaui sediaan untuk dapat memecah ikatan polimer carbopol sehingga dapat menggerakkan spindle alat yang digunakan. Pada pengukuran FI 1dan F2 menggunakan spindle nomor 64, sedangkan F3 menggunakan spindle nomor 63, menunjukkan bahwa F3 memiliki viskositas yang paling kecil dibandingkan F1 dan F2. Pada F1 kecepatan perputaran spindle dengan torsi maksimal yang memenuhi syarat adalah 20 RPM, sedangkan F2 adalah 100 RPM. Semakin tinggi RPM menandakan semakin rendah viskositas sediaan. Hal ini menunjukkan viskositas F1 lebih tinggi daripada F2 dan semakin besar proporsi propilen glikol yang digunakan sebagai enhancer akan meningkatkan viskositas emulgel MABC yang dibuat. Berdasarkan uji daya lekat dan daya sebar dan $\mathrm{pH}$ diperoleh nilai rata-rata tiap formula seperti terlihat pada Tabel III.

Tabel III. Hasil uji sifat fisik emulgel MABC

\begin{tabular}{lcccc}
\hline \multicolumn{1}{c}{ Uji Sifat Fisik } & F1 & F2 & F3 & F4 \\
\hline pH & $6,62 \pm 0,01$ & $6,56 \pm 0,01$ & $6,04 \pm 0,03$ & $7,55 \pm 0,03$ \\
Daya sebar $\left(\mathbf{c m}^{2}\right)$ & $7,22 \pm 0,41$ & $8,38 \pm 0,69$ & $10,37 \pm 0,77$ & $6,30 \pm 0,08$ \\
Daya lekat (menit) & $9,10 \pm 0,73$ & $3,12 \pm 0,55$ & $1,84 \pm 0,46$ & $18,37 \pm 0,66$
\end{tabular}

Keterangan :

$\mathrm{F} 1$ : emulgel MABC dengan penambahan enhancer propilen glikol $10 \mathrm{~g}$

F2 : emulgel MABC dengan penambahan enhancer propilen glikol $5 \mathrm{~g}$ dan asam oleat $5 \mathrm{~g}$

F3 : emulgel MABC dengan penambahan enhancer asam oleat $10 \mathrm{~g}$

F4 : emulgel MABC tanpa penambahan enhancer

Uji daya sebar dilakukan untuk mengetahui kemampuan sediaan menyebar pada kulit, dimana suatu sediaan emulgel sebaiknya memiliki daya sebar yang baik untuk menjamin pemberian bahan obat yang baik. Persyaratan daya sebar untuk sediaan topikal yaitu sekitar 5-7 $\mathrm{cm}^{2}$ (Ulaen, Banne and Suatan, 2004). Data hasil uji daya sebar emulgel pada F1, F2 dan F3 menghasilkan daya sebar 7-10 $\mathrm{cm}^{2}$. Hal ini menandakan bahwa emulgel yang dihasilkan mempunyai konsistensi fisik yang cenderung encer sehingga memiliki daya sebar yang tinggi. Konsistensi yang encer tersebut tidak menjadi masalah apabila emulgel mempunyai daya lekat yang baik dan memenuhi syarat. Hasil daya lekat menunjukkan bahwa emulgel mempunyai daya lekat yang baik dan memenuhi syarat walaupun konsistensi nya cenderung encer. Hal ini dikarenakan di dalam formulasi emulgel MABC yang dibuat menggunakan basis gelling agent carbopol 940 yang merupakan suatu polimer yang mempunyai kemampuan berlekatan secara fisik sangat baik dengan kulit. 
Daya lekat yang dihasilkan lebih dari 1 menit. Penelitian sebelumnya menyebutkan bahwa daya lekat sediaan topikal tidak kurang dari 4 detik (Ulaen, Banne and Suatan, 2004). Daya lekat yang lama pada permukaan kulit diharapkan dapat memperlama kontak antara zat aktif dengan kulit dan dengan adanya enhancer propilen glikol dapat meningkatkan kemampuan penetrasi eugenol dalam menembus lapisan stratum korneum kulit. Hal ini menunjukkan bahwa semakin besar proporsi propilen glikol sebagai enhancer dalam sediaan emulgel MABC akan semakin meningkatkan daya lekat sediaan emulgel. Hasil perbandingan kombinasi enhancer propilen glikol dan asam oleat antara uji daya lekat dan uji daya sebar berkebalikan karena semakin tinggi tingkat konsistensi sediaan akan semakin lama daya lekat nya namun semakin kecil luas area daya sebarnya atau semakin besar proporsi propilen glikol sebagai enhancer akan menurunkan daya sebar emulgel
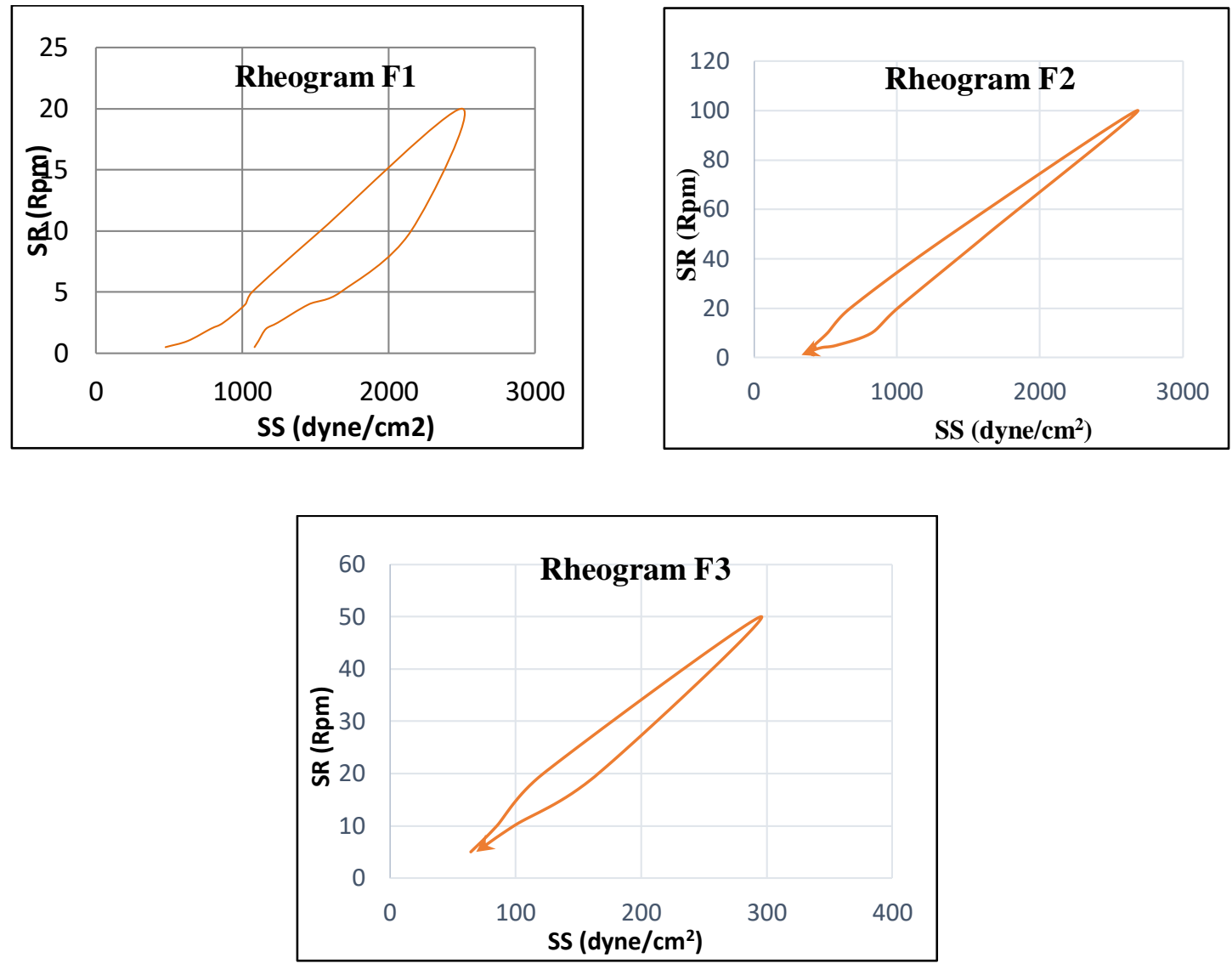

Gambar 3. Rheogram F1, F2 dan F3

Emulgel yang dihasilkan dari F1, F2, dan F3 mempunyai nilai pH 6,63; 6,56; dan 6,02. Nilai $\mathrm{pH}$ ini sudah sesuai dengan $\mathrm{pH}$ kulit, karena $\mathrm{pH}$ sediaan emulgel harus sesuai dengan $\mathrm{pH}$ kulit agar tidak menimbulkan iritasi kulit pada saat pemakaian. Dari hasil terlihat bahwa penambahan propilen glikol sebagai enhancer akan membuat $\mathrm{pH}$ sediaan emulgel semakin basa dan penambahan enhancer asam oleat akan menjadikan $\mathrm{pH}$ sediaan emulgel semakin asam

\section{KESIMPULAN}

Enhancer propilen glikol dan asam oleat mampu secara signifikan meningkatkan nilai flux dan daya permeabilitas eugenol menembus lapisan stratum corneum kulit dan memiliki karakteristik fisik berupa nilai $\mathrm{pH}$, viskositas, daya lekat dan daya sebar yang memenuhi kriteria. 


\section{UCAPAN TERIMAKASIH}

Penelitian ini terselenggara atas bantuan Hibah DIKTI melalui skema penelitian Tim Pasca Sarjana Tahun Anggaran 2016.

\section{DAFTAR PUSTAKA}

Arellano, A. et al. (1999) 'Influence of propylene glycol and isopropyl myristate on the in vitro percutaneous penetration of diclofenac sodium from carbopol gels', European Journal of Pharmaceutical Sciences, $\quad 7(2), \quad$ pp. 129-135. doi: 10.1016/S0928-0987(98)00010-4.

Banweer, J., Pandey, S. and Pathak, A. K. (2010) 'Development and Optimization of Transdermal System of Lisinopril dehydrate: Employing Permeation Enhancers', 6(4), pp. 245-251.

Chantasart, D. and Kevin Li, S. (2012) 'Structure enhancement relationship of chemical penetration enhancers in drug transport across the stratum corneum', Pharmaceutics, 4(1), pp. 71-92. doi: 10.3390/pharmaceutics4010071.

Elmoslemany, R. M. et al. (2012) 'Propylene Glycol Liposomes as a Topical Delivery System for Miconazole Nitrate: Comparison with Conventional Liposomes', 13(2). doi: 10.1208/s12249- 012-9783-6.

Engelbrecht, T. N. et al. (2011) 'Biochimica et Biophysica Acta Lipophilic penetration enhancers and their impact to the bilayer structure of stratum corneum lipid model membranes: Neutron diffraction studies based on the example Oleic Acid', BBA - Biomembranes. Elsevier B.V., $\quad$ 1808(12), pp. 2798-2806. doi: 10.1016/j.bbamem.2011.08.012.

Kamatou, G. P., Vermaak, I. and Viljoen, A. M. (2012) 'Eugenol-From the Remote Maluku Islands to the International Market Place: A Review of a Remarkable and Versatile Molecule', pp. 6953-6981. doi: 10.3390/molecules17066953.

Khullar, R. et al. (2012) 'Formulation and evaluation of mefenamic acid emulgel for topical delivery', Saudi Pharmaceutical Journal. King Saud University, 20(1), pp. 63-67. doi: 10.1016/j.jsps.2011.08.001.

Naibaho, O. H., Yamlean, P. V. Y. and Wiyono, W. (2013) 'Pengaruh Basis Salep Terhadap Formulasi Sediaan Salep Ekstrak Daun Kemangi (Ocimum sanctum L.) Pada Kulit Punggung Kelinci yang Dibuat Infeksi Staphylococcus aureus', Jurnal Ilmiah Farmasi-UNSRAT, 2(02), pp. 27- 34.

Raut, S. V. et al. (2014) 'Chemical Penetration Enhancers : For Transdermal Drug Delivery Systems', International Journal of Pharmaceutics, 4(1), pp. 33-40.

Rakesh, R., Anoop, K.R., 2012, Formulation and Optimization of Nano-sized Ethosomes for Enhanced Transdermal Delivery of Cromolyn Sodium, Journal of Pharmacy and Bioalled Sciences, 4(4) : 333-340.

Sari, D. K., Sugihartini, N. and Yuwono, T. (2015) 'Evaluasi Uji Iritasi Dan Uji Sifat Fisik Sediaan Emulgel Minyak Atsiri Bunga Cengkeh (Syzigium aromaticum )', Pharmaciana, 5(2), pp. 115-120.

Sugihartini, N., 2013, Optimasi Komposisi Enhancer dan Emulgator pada Formulasi Krim Fraksi Etil Asestat Ekstrak Teh Hijau (Camellia sinensis, L) sebagai Sediaan Topikal Anti Inflamasi, Disertasi, Program Pascasarjana Universitas Gadjah Mada, Yogyakarta.

Trommer, H. and Neubert, R. H. H. (2006) 'Overcoming the stratum corneum: The 
modulation of skin penetration. A review', Skin Pharmacology and Physiology, 19(2), pp. 106-121. doi: $10.1159 / 000091978$.

Ulaen, S. P. J., Banne, Y. and Suatan, R. a (2004) 'Pembuatan Salep Anti Jerawat Dari Ekstrak Rimpang Temulawak ( Curcuma xanthorrhiza Roxb.)’, Politeknik Kesehatan Kemenkes Manado. 
